\title{
Labio-maxillo-palatal clefts: morphological and embryological aspects
}

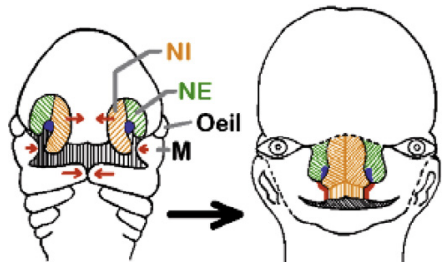

\author{
Marie DUCREUX, Alain DUVERNAY, Gabriel MALKA, \\ Pierre TROUILLOUD, Olivier TROST
}

ABSTRACT

The designation labio-maxillo-palatal cleft is used to describe two types of congenital malformations of the palate. The mechanisms that create them occur in the early weeks of fetal life by an alteration of embryological message delivery that researchers have been able to analyze. But they have not as yet been able to discern the multi-factorial causes of this alteration.

Morphological embryology and its chronology are important because researchers use an understanding of them to distinguish between different entities of clefts on the basis of the stage of palatal formation in which they began to develop: the numerous molecules involved In cell development are already well known, but researchers have not yet precisely identified those that are associated with the various stages of palatal morphogenesis. But it is clear that genetic alterations, which are now being pin-pointed, trigger developmental malfunctionings that are later intensified by faulty interactions in the fetalmaternal environment because.

Conclusion: Although researchers are progressively gaining a better understanding of the mechanisms of the intra-uterine formation of labiomaxillo-palatal clefts, we have not yet acquired the broad range of data that would make it possible to correct defective palatal formation before birth.

\section{KEYWORDS}

Labio-maxillo-palatal cleft

Cranio-facial embryology

Congenital malformation

Address for correspondence:

O. TROST,

Service de chirurgie maxillo-faciale et stomatologie,

Received: 04-2011.

Hôpital du Bocage,

Accepted: 06-2011.

C.H.U. de Dijon,

2 avenue de Lattre de Tassigny,

21000 Dijon.

olivier.trost@chu-dijon.fr 


\section{INTRODUCTION}

Labio-maxillo-palatal clefts are the most frequently appearing congenital malformations in the general population, occurring in one of every 1000 births.

For parents who do not themselves suffer from this disorder but already have a child with a cleft, the chances that the next infant conceived would be afflicted will be $4 \%$, and $9 \%$ if they have two afflicted children.

Caregivers can discern osseous clefts in fetuses with ultra-sound but clefts that involve only the lips or are isolated palatal defects are difficult to uncover before birth. Sometimes clefts are only one aspect of a more diffused deformity.
Various forms of non-syndromic labial clefts - with or without associated palatal defects - affect 1 out of 300 to one out of 2500 newborns. The incidence for isolated palatal clefts is one out of $1500^{14}$. This value varies according to region ${ }^{10,15}$ and primarily occurs in Asiatic and American Indian populations.

In all their configurations, the consequences of clefts on the future development of the dentition, speaking ability, and other capabilities require on-going care by a variety of specialists in addition to the initial surgical repair.

\section{MORPHOLOGICAL EMBRYOLOGY OF THE PALATE}

The palatal osseous tissue derives from embryonic mesenchyme, formed from the mesoderm and neural crests. Anatomically, the mesenchyme is encircled by two embryonic epithelial tissues: ectoblast on the surface and endoblast internally. These two structures serve as a kind of guide for the expansion of the adjacent mesenchyme.

The morphogenesis of the palate takes place in two distinct stages, chronologically as well as biologically. In the first, the lip and the primary palate begin to take shape and in the second stage the secondary palate starts its formation.

Between the $5^{\text {th }}$ and the $10^{\text {th }}$ weeks of embryonic life the face and the anterior portions of the nasal fossas begin to form out of the five me- senchymal buds corresponding to the first branchial arch: the median frontal eminence, the internal nasal buds, the external nasal buds, the maxillary buds, and the mandibular buds.

Primary palatal formation starts at the same time the lip begins to take shape and corresponds to the peripheral part of the palate. It is triangular and occupies an anterior position. During the fifth week of embryonic development the inferior and ventral portion of the frontal bud becomes the seat of the development of the internal and external nasal buds, which are cellular masses that propagate themselves thanks to mitosis of cells of the neural crest.

During the $6^{\text {th }}$ week, the internal nasal buds form along the median line, then extend downward in the direc- 
tion of the maxillary buds to close the upper dental arch (fig. 1). This contact constitutes the "epithelial wall of
Hochstetter," which dissolves soon after and removed by underling mesenchymal phagocytes to allow

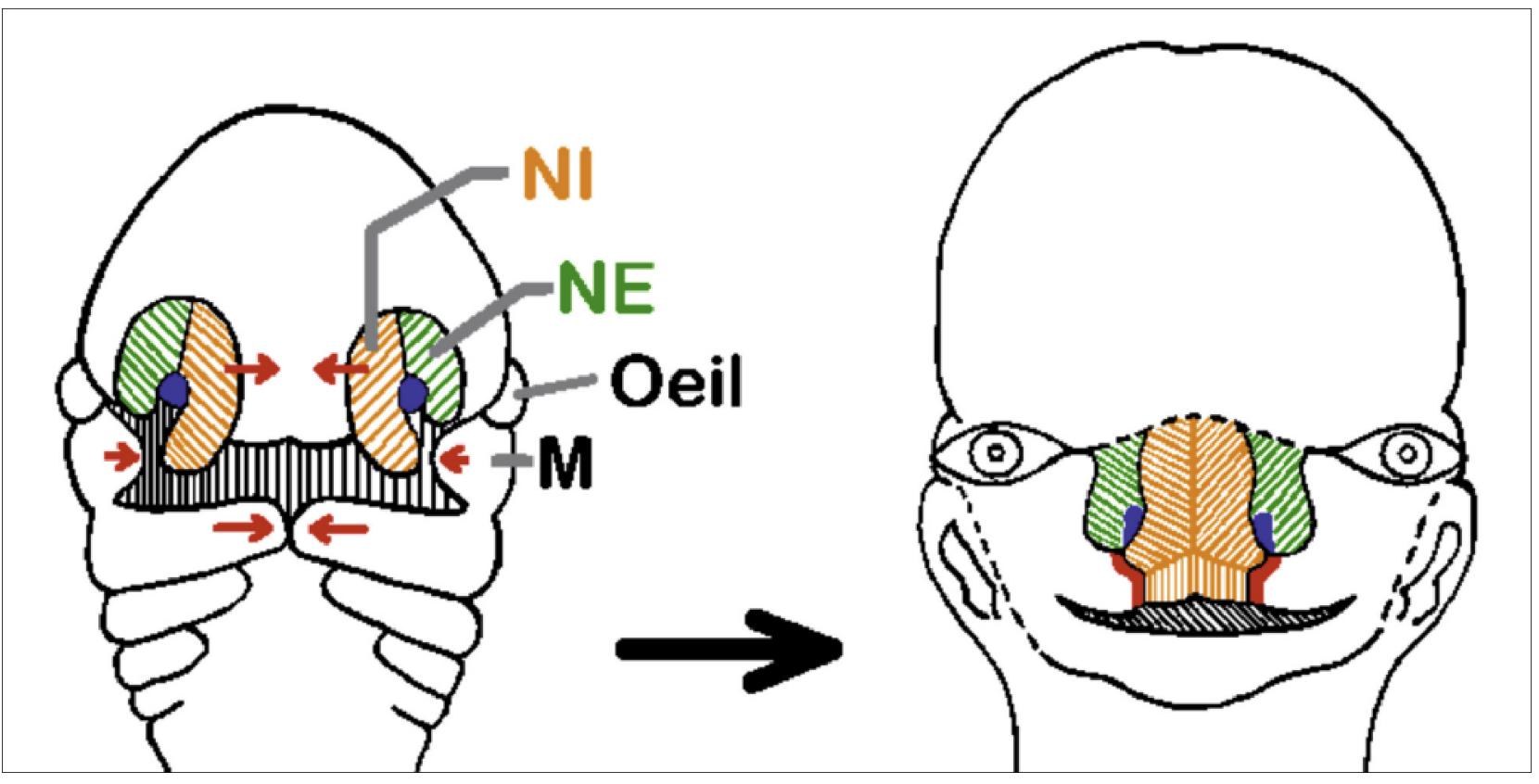

Figure 1

Migration of the internal buds (in orange) toward the maxillary buds (M) and closure of the maxillary dental arch.

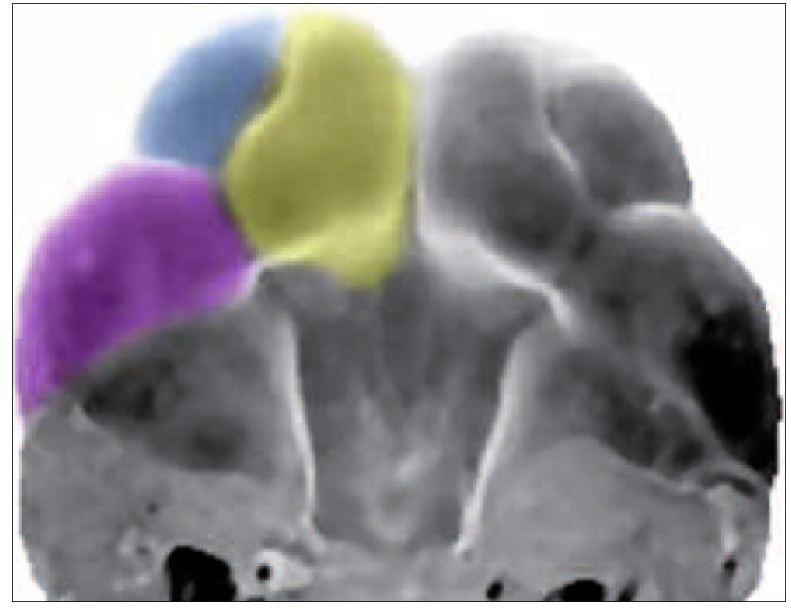

Figure 2

Advancement of the maxillary bud. Intraoral view of the formation of the primary palate. The maxillary bud (in red), after having crossed under the external nasal bud (in blue), and reached the internal nasal bud (in yellow).

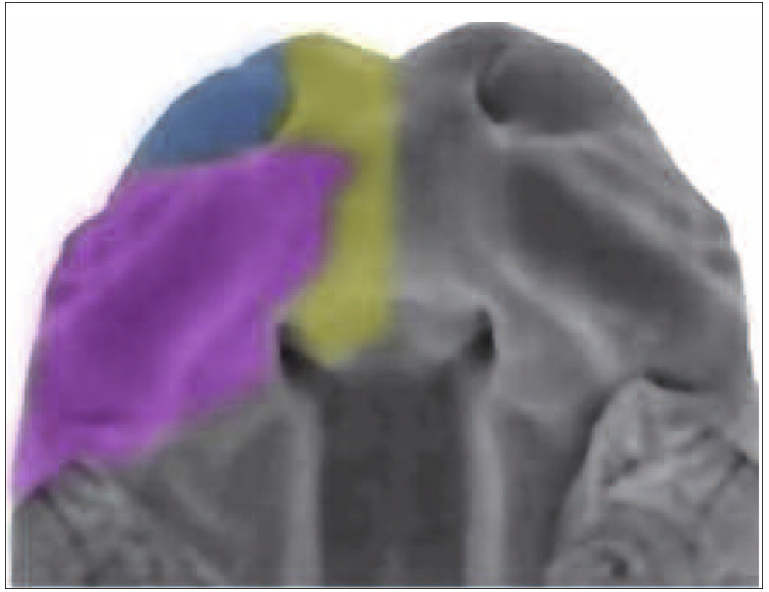

Figure 3

The fusion that creates the primary palate. When fusion of the maxillary bud with the nasal bud is completed, the primary palate is formed but communication between the mouth and the nasal fossas is still widely open. 


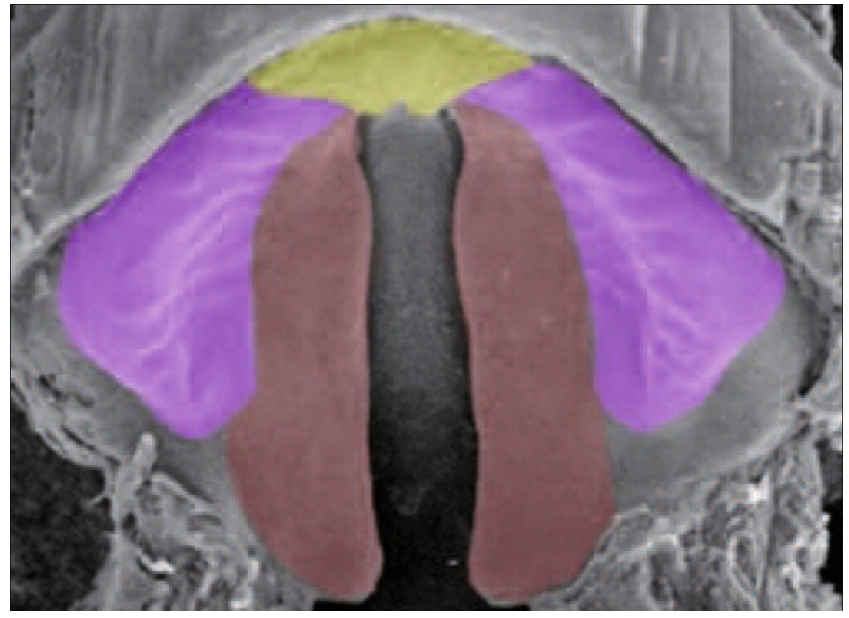

Figure 4

The median septum. Descending from the roof of the nasal fossas, the septum will divide the nasal cavity into left and right sections.

creation of a continual mesenchymal cellular mass arising from the neural crest that is called the "primary palate" (fig. 2).

After the maxillary bud fuses with the nasal bud, the primary palate is essentially complete, but the mouth and the nasal fossas still have substantial open communication (fig. 3). When the maxillary bud fails to fuse with the internal nasal bud clefts are created in the labio-nasal area and the primary palate that will later interfere with the migration of odontoblasts and of myocytes. This explains why afflicted patients have soft palate defects that prevent nursing infants from being properly nourished and developing normal speaking and hearing capacities as well as interfering with normal tooth eruption patterns.

In the $7^{\text {th }}$ week of intra-uterine life two longitudinal buds, the palatal processes, appear on the internal surface of the maxillary buds (fig. 4). They initially move downward then shift

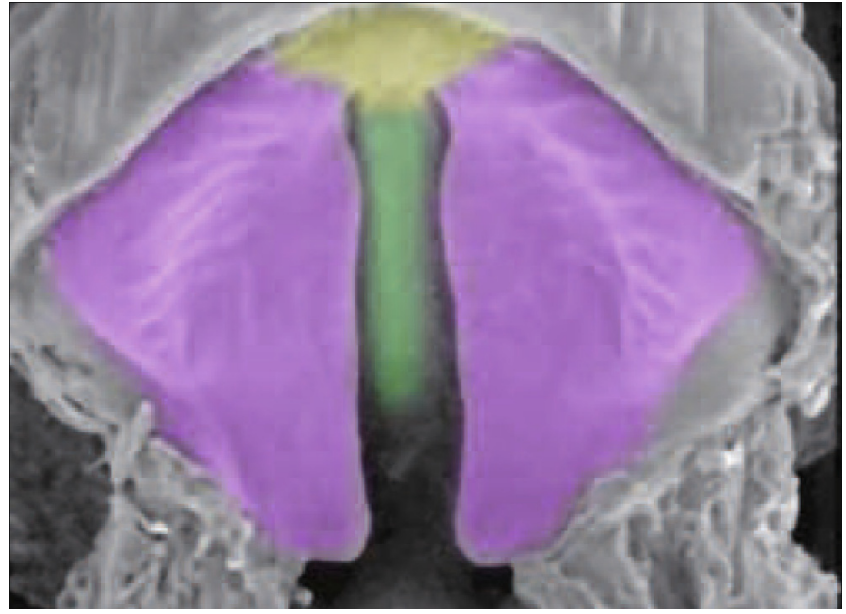

Figure 5

The palatal processes. Two other lateral processes (red) emerge from the lateral sectors of the primary palate (violet). They will separate the mouth from the nose.

above the beginning structure of the tongue to complete their vertical growth. At the $9^{\text {th }}$ week they merge in front of the primary palate, then fuse along a median line from the mesial to the distal to form the secondary palate that separates the nasal fossas from the oral cavity. This growth process continues until the $12^{\text {th }}$ week.

Finally, a septum that descends from a sagittal divider in the upper portion of the primitive nasal fossa separates the nasal fossa into a right and left nostril, joining with the primary palate in the $10^{\text {th }}$ week. The posterior portion of this septum, or columella, later merges with the palatal processes (fig. 5).

Once the various structures have fused, an ensemble of epithelio-mesenchymal interactions in which the extra-cellular matrix and soluble agents like collagen and the Epidermal Growth Factor participate. 


\section{MOLECULAR FACTORS IN EMBRYONIC DEVELOPMENT OF THE PALATE}

Growth of different buds must be coordinated during the various stages of the morphogenesis of the palate. They cannot fuse properly if ectoblasts disappear from contact zones because of apoptosis.

But because of the complexity of the mechanisms involved teratogenic factors such as vitamin $A$ and antiepileptics frequently provoke cell death.

Some of the resulting physio-pathological developments are:

- non-syndromic clefts, in 70 to 90\% of the cases, including:

- labial clefts with or without a palatal defect;

- isolated palatal clefts;

- syndromic clefts are implicated in various polyformative syndromes.

Many authors direct their attention to cellular and molecular targets as being the root causes of non-syndromic oro-facial clefts. An inspection of the relevant literature reveals that certain body sites play host to recurrent polymorphisms that are associated with clefts. In the same way, many molecular agents that have been identified as key actors in the morphogenesis of the palate undergo alterations that end up in creating clefts.

Nobuko Hagiwara and her team ${ }^{2}$ have shown that GABAergic neurons participate in the phenomena of cell migration during formation of the secondary palate. The rate of production of GABA - an important component of nerve tissue - varies during different developmental stages within the embryonic mesenchyme. Mutations of the genetic code for the subunit b32 may introduce perturbations of this signaling pathway. Although the GABAergic's mode of expression outside of nerve tissue remains unknown, neurological tropism molecules like Diazepam or other anticonvulsants have been shown to have an inhibitory effect on the vertical growth of the palatal processes by acting on this pathway ${ }^{13}$.

In addition, genome studies have made it possible for researchers to identify as many ten sites involved in the unexpected creation of labial or labio-palatal clefts, but only one site associated with the development of isolated palatal clefts, (locus 2q32: coded for TGF $\alpha)^{5}$. This datum supports the notion that formation of the primary palate and of the secondary palate are two quite distinct procedures $^{1}$. Moreover, these studies have also discerned the existence of clefts related to the $X$ chromosome that are caused by a defect on it coded for the transcription factor T-box, (TBX22): this molecule plays an essential role in the early intra-uterine development of mammals, notably in the differentiation of the mesenchyme ${ }^{8}$. All these genes are coded for proteins that play a preponderant role in cellular differentiation, migration, and adhesion. Accordingly, IRF6 (Interferon Regulatory Factor 6), the transcription factor, and the TGFA gene that codes the protein that is related to the epidermal receptor of the growth factor, EGF, are also implicated. Nevertheless, not all studies of gene mutations agree that 
there is a significantly increased risk of cleft development associated with the mutations we have described.

Mutations of the genes involved in the synthesis of participants in folate metabolism, Reduced Folate Carrier ${ }^{12}$ or MTHFD (Methylenetetrahydrofolate dehydrogenase gene $)^{7}$ can also exert an effect on the morphogenesis of the palate. Similarly, numerous published articles have noted that a mother's increased intake of iron at the time of conception can diminish the risk of the fetus's developing clefts ${ }^{4,11}$. On the other hand, low intake of folates by the mother can increase that risk $^{9}$.

\section{CONCLUSION}

The pathological mechanisms that produce orofacial clefts operate at the beginning of embryonic development. They affect the two stages of palatal formation in distinctly different ways, which makes it difficult for researchers to evaluate them. Moreover, there are also interferences in a number of signaling pathways that add additional cleft provoking defects.

But we do not yet have sufficient currently available data that would permit successful in utero intervention to prevent cleft formation although a mother's adherence to certain good
The interaction of environmental factors with normal biological processes increases the complexity of the physiopathology of orofacial clefts. Excessive use of alcohol, tobacco, and anti-convulsants can trigger developmental anomalies in the embryo's cephalic extremity ${ }^{3}$ by altering the composition of the extra-cellular matrix, by modifying, through fibroblast action, the synthesis of diverse molecules such as the integrins that mediate cellular adhesion to surrounding tissues and the matrix metalloproteinase (MMPs) that regulate the action of enzymes participating in the formation of collagen fibers ${ }^{6}$.

health protocols around the time of conception may be helpful.

Further studies are needed to discern the key actors in palatal morphogenesis including examination of interferences caused by diverse exogenic factors.

At the present time management of palatal malformations consists of a mother's avoiding harmful exogenic influences and the after-the-fact medical-surgical, multidisciplinary treatment of afflicted children at an early age supplemented by long-term follow-up therapy.

\section{REFERENCES}

1. Carinci F, Scapoli L, Palmieri A, Zollino I, Pezzetti F. Human genetic factors in nonsyndromic cleft lip and palate: an update. Int $\mathrm{J}$ Pediatr Otorhinolaryngol 2007;71:1509-19.

2. Hagiwara N, Katarova Z, Siracusa LD, Brilliant MH. Nonneuronal expression of the GABA(A) beta3 sub- unit gene is required for normal palate development in mice. Dev Biol 2003;254:93-101. 
3. Hanson JW, Myrianthopoulos NC, Harvey MA, Smith DW. Risks to the offspring of women treated with hydantoin anticonvulsants, with emphasis on the fetal hydantoin syndrome. J Pediatr 1976;89:662-8.

4. Hayes C, Werler MM, Willett WC, Mitchell AA. Case-control study of periconceptional folic acid sup- plementation and oral clefts. Am J Epidemiol 1996;143:1229-34.

5. Marazita ML, Murray JC, Lidral AC, et al. Meta-analysis of 13 genome scans reveals multiple cleft lip/palate genes with novel loci on 9q21 and 2q32-35. Am J Hum Genet 2004;75:161-73.

6. Marinucci L, Balloni S, Bodo $\mathrm{M}$, et al. Patterns of some extracellular matrix gene expression are simi- lar in cells from cleft lip-palate patients and in human palatal fibroblasts exposed to diazepam in culture. Toxicology 2009;257:10-6.

7. Mills JL, Molloy AM, Parle-McDermott A, Troendle JF, Brody LC, Conley MR, et al. Folate-related gene polymorphisms as risk factors for cleft lip and cleft palate. Birth Defects Res A Clin Mol Teratol 2008;82:636-43.

8. Moore GE, Ivens A, Chambers J, et al. Linkage of an X-chromosome cleft palate gene. Nature 1987;326:91-2.

9. Munger RG, Tamura T, Johnston KE, et al. Oral clefts and maternal biomarkers of folatedependent on carbon metabolism in Utah. Birth Defects Res A Clin Mol Teratol 2011;91:153-61.

10. Murray JC. Gene/environment causes of cleft lip and/or palate. Clin Genet 2002;61:24856.

11. Van Rooij IA, Ocke MC, Straatman H, Zielhuis GA, Merkus HM, Steegers-Theunissen RP. Periconcep- tional folate intake by supplement and food reduces the risk of nonsyndromic cleft lip with or without cleft palate. Prev Med 2004;39:689-94.

12. Wang Y, Song X, Guo J, Zhu W. Relationship between genetic polymorphisms of RFC1 A80G and non- syndromic cleft lip with or without palate. Wei Sheng Yan Jiu 2009;38:276-9.

13. Wee EL, Zimmerman EF. Involvement of GABA in palate morphogenesis and its relation to diazepam teratogenesis in two mouse strains. Teratology 1983;28:15-22.

14. Wyszynski DF, Beaty TH, Maestri NE. Genetics of nonsyndromic oral clefts revisited. Cleft Palate Craniofac J 1996;33:406-17.

15. Wyszynski DF, Wu T. Use of US birth certificate data to estimate the risk of maternal cigarette smoking for oral clefting. Cleft Palate Craniofac J 2002;39:188-92. 